\title{
PROJEÇÃO DO ESTOQUE DE CARBONO E ANÁLISE DA GERAÇÃO DE CRÉDITOS EM POVOAMENTOS DE EUCALIPTO ${ }^{1}$
}

\author{
Rodrigo Firmino da Silva ${ }^{2}$, Carlos Pedro Boechat Soares ${ }^{3}$, Laércio Antonio Gonçalves Jacovine ${ }^{3}$, Márcio
} Lopes da Silva ${ }^{3}$, Helio Garcia Leite ${ }^{3}$ e Gilson Fernandes da Silva ${ }^{4}$

\begin{abstract}
RESUMO - Este estudo teve como objetivo predizer a produção volumétrica e o estoque de carbono nos fustes das árvores em povoamentos de eucalipto, bem como avaliar economicamente a inclusão dos Certificados de Emissões Reduzidas (CERs) nos projetos florestais através de critérios quantitativos. Para isso, utilizaramse dados de povoamentos de Eucalyptus grandis localizados no Município de Guanhães, MG, Minas Gerais. De posse das equações de volume e carbono para o fuste das árvores individuais e de 95 parcelas permanentes, ajustou-se o modelo de crescimento e produção de Clutter (1983) para projeção da produção volumétrica e do estoque de carbono. Após as análises, verificou-se que: a) o modelo de crescimento e produção proposto por Clutter (1983) propiciou idades técnicas de colheita coerentes com a capacidade produtiva dos povoamentos, tanto para a produção volumétrica quanto para o estoque de carbono; b) as idades técnicas de colheita (ITCs) foram praticamente iguais, considerando-se o estoque volumétrico e o estoque de carbono; c) as rotações econômicas foram maiores do que as idades técnicas de colheita (ITCs) em locais de baixa e média produtividades ( $\mathrm{S}=$ 20 e S = 26), independentemente da inclusão ou não dos CERs; d) os CERs contribuem para a viabilidade financeira dos projetos florestais em locais de baixa produtividade, quando se considera que as receitas sejam auferidas no ano de implantação do projeto; e) na análise de sensibilidade, o preço da madeira foi o item que mais influenciou a viabilidade econômica dos projetos. No entanto, os Certificados de Emissões Reduzidas tiveram pouca influência.
\end{abstract}

Palavras-chave: Seqüestro de carbono, biomassa florestal e eucalipto.

\section{CARBON STOCK PROJECTION AND CREDIT GENERATION ANALYSIS IN EUCALYPT STANDS}

\begin{abstract}
The objectives of this study were to predict volumetric yield and carbon stock in the stems of eucalypt plantation trees, as well as to economically evaluate the inclusion of the Reduced Emission Certificates (RECs) in forest projects by quantitative criteria. Thus, data from Eucalyptus grandis stands, located in GuanhãesMinas Gerais, were used. Based on the volume and carbon equations for the stems of individual trees and for 95 permanent plots, Clutter growth and production model (1983) were adjusted for volumetric production and carbon stock projection. After analysis, it was verified that: a) the growth and yield model proposed by Clutter (1983) provided technical cutting ages according to the productivity capacity of the stands, both for volumetric yield and carbon stock; $b$ ) the technical cutting ages (TCAs) were practically the same, considering the volumetric and carbon stocks; $c)$ the economic rotations were greater than the technical cutting age in sites with low and average productivity $(S=20$ and $S=26)$, regardless of the inclusion or not of the CERs in the analysis; $d$ ) the CERs contributed to the economic viability of the forest projects in low productivity sites, considering the budgets for the establishment of the projects; $e$ ) in the sensitivity analysis, the item wood price had the greatest influence on the economic viability of the projects. In contrast, the Reduced Emission Certificates (RECs) had little influence.
\end{abstract}

Keywords: Carbon sequestration, forest biomass and eucalypt.

\footnotetext{
${ }^{1}$ Recebido em 27.03.2007 e aceito para publicação em 22.08.2008.

${ }^{2}$ Programa de Pós-Graduação em Ciência Florestal da Universidade Federal de Viçosa (UFV). E-mail: < rodfir@ yahoo.com.br>.

${ }^{3}$ Departamento de Engenharia Florestal da UFV. E-mail: <csoares@ ufv.br>.

${ }^{4}$ Centro de Ciências Agrárias da Universidade Federal do Espírito Santo (UFES). E-mail: <gfsilva@ @ca.ufes.br>
} 


\section{INTRODUÇÃO}

A partir da década de 1980 , questões relativas às mudanças climáticas, ao aquecimento global e ao efeito-estufa passaram a ser destaques como ameaças ambientais que colocam em risco a integridade do planeta. Tais questões ganharam importância mundial, culminando na criação da Convenção Quadro das Nações Unidas sobre Mudanças Climáticas Globais.

As primeiras negociações internacionais referentes às mudanças climáticas ocorreram na ECO-92, no Rio de Janeiro, em 1992. Desde o início das discussões, os usos da terra e das florestas eram contemplados como mecanismos para mitigar as mudanças climáticas e, como um primeiro passo concreto nessa direção, em 1997, na Convenção das Partes-3 (COP-3), foi criado o Protocolo de Quioto.

A partir do estabelecimento dos mecanismos de flexibilização, como o Mecanismo de Desenvolvimento Limpo (MDL), o foco da discussão voltou-se para o seqüestro de carbono pelas florestas como uma das alternativas de compensação das emissões dos países industrializados (YU, 2002).

No caso das florestas, o desmatamento e as queimadas contribuem para agravar o efeito-estufa, uma vez que liberam o $\mathrm{CO}_{2}$ para a atmosfera. Mas, quando se conservam, preservam, recuperam ou plantam florestas, ocorre um processo inverso devido ao surgimento de um sumidouro de carbono, uma vez que as florestas removem parte do $\mathrm{CO}_{2}$ da atmosfera através do processo de fotossíntese, promovendo o chamando "seqüestro de carbono".

A possibilidade de os países contabilizarem o seqüestro de carbono pelas florestas nos seus inventários nacionais de emissões criou uma nova perspectiva para o setor florestal. No entanto, são ainda escassos estudos de mensuração florestal e de viabilidade econômica de projetos, visando ao desenvolvimento de técnicas e métodos para a quantificação do estoque de carbono presente na biomassa florestal (PAIX ̃̃O et al., 2006). Com estudos desta natureza, o setor florestal pode se destacar no mercado de créditos de carbono, já que as florestas, principalmente as plantadas, terão ainda mais valor agregado aos seus recursos.

Nesse contexto, o Brasil poderá se beneficiar e assumir posição privilegiada perante os países que buscam reverter o processo de mudança climática, tanto do ponto de vista de reduções das emissões quanto em projetos de seqüestro de carbono, já que possui potencialidades e tecnologias que o difere dos demais países (ROCHA, 2002).

Esse novo mercado, portanto, tem o potencial de gerar um fluxo de capital para as atividades florestais brasileiras, em que o setor florestal oferece oportunidades inigualáveis de compensação de carbono através do MDL. No entanto, a natureza e magnitude dessas oportunidades dependerão de como será interpretado e de como serão contabilizados os "créditos de carbono".

Diante do exposto, este estudo teve como objetivos predizer a produção volumétrica e o estoque de carbono nos fustes das árvores em povoamentos de eucalipto e avaliar economicamente a inclusão dos Certificados de Emissões Reduzidas (CERs) nos projetos florestais através de critérios quantitativos.

\section{MATERIAL E MÉTODOS}

Este estudo foi realizado com dados de povoamentos de Eucalyptus grandis, plantados no espaçamento $3 \mathrm{~m}$ x $2 \mathrm{~m}$, com idades variando de 32 a 80 meses, de propriedade da Empresa Florestal Celulose Nipo-Brasileira - CENIBRA S/A, no Município de Guanhães, MG, na região do Alto e Médio Rio Doce.

Para o ajuste das equações de volume e de carbono para os fustes das árvores foram utilizadas 532 árvores, distribuídas em diferentes classes de diâmetros. Em cada árvore-amostra foram medidos o DAP (diâmetro com casca a $1,30 \mathrm{~m}$ do solo) e a altura total $(H t)$, bem como realizado o procedimento de cubagem rigorosa para a obtenção do volume do fuste com e sem casca. Além disso, foram retirados discos de madeira e casca para a determinação das densidades básicas da madeira e da casca, de acordo com Vital (1985), que, multiplicados pelos respectivos volumes, forneceram as estimativas de biomassa de madeira e da casca do fuste.

Para obter as estimativas de carbono estocado nos fustes das árvores-amostra (madeira + casca), as estimativas de biomassa foram multiplicadas por um fator igual a 0,5 , ou seja, foi assumido que $50 \%$ da biomassa era composta por carbono (SOARES e OLIVEIRA, 2002).

De posse das informações de $D A P$ e $H t$, do volume com casca e do carbono no fuste de cada árvore-amostra, foram ajustadas equações referentes ao modelo de Schumacher e Hall (1933), cuja relação funcional é dada por: 


$$
L n Y=\beta_{o}+\beta_{1} L n D A P+\beta_{2} L n H t+\varepsilon
$$

em que:

$L n=$ logaritmo neperiano;

$Y=$ volume total com casca, $\mathrm{em}^{3}$; ou carbono total no fuste (madeira+casca), em kg;

$D A P=$ diâmetro com casca medido a $1,30 \mathrm{~m}$ do solo, em cm;

$H t=$ altura total da árvore, em metros;

$\beta_{0}, \ldots, \beta_{2}=$ parâmetros do modelo; e

$\varepsilon=$ erro aleatório.

As equações que estimam o volume e o carbono das árvores individuais foram utilizadas para totalizar 95 parcelas permanentes medidas entre 1996 e 2000. As estimativas das parcelas foram, então, utilizadas no ajuste das equações referentes ao modelo de crescimento e produção de Clutter (1983), dado por:

$$
\left\{\begin{array}{l}
\operatorname{Ln} Y_{2}=\beta_{0}+\frac{\beta_{1}}{I_{2}}+\beta_{2} S+\beta_{3} \operatorname{Ln} B_{2}+\varepsilon \\
\operatorname{Ln} B_{2}=\operatorname{Ln} B_{1}\left(\frac{I_{1}}{I_{2}}\right)+\beta_{4}\left(1-\frac{I_{1}}{I_{2}}\right)+\beta_{5}\left(1-\frac{I_{1}}{I_{2}}\right) S+\varepsilon
\end{array}\right.
$$

em que:

$Y_{2}=$ produção volumétrica futura ou estoque de carbono futuro, em $\mathrm{m}^{3} / \mathrm{ha}$ ou $\mathrm{kg} / \mathrm{ha}$, respectivamente;

$I_{1}=$ idade presente, em meses;

$I_{2}=$ idade futura, em meses;

$B_{1}=$ área basal presente, em $\mathrm{m}^{2} / \mathrm{ha}$;

$B_{2}=$ área basal futura, em $\mathrm{m}^{2} / \mathrm{ha}$;

$S=$ índice de sítio $(\mathrm{m})$; e

$\beta_{0}, \ldots, \beta_{5}=$ parâmetros do modelo.

Para avaliar a precisão das equações ajustadas foram utilizados o coeficiente de determinação $\left(\mathrm{R}^{\mathbf{2}}\right)$, o erro-padrão da estimativa $\left(S_{y . x}\right)$, o coeficiente de variação (CV\%) e a distribuição gráfica dos resíduos em porcentagem $(\mathrm{R} \%)$, obtida por:

$$
R(\%)=\frac{Y_{e s t .}-Y_{o b s .}}{Y_{o b s .}} * 100
$$

em que:

Yest.$=$ volume estimado, com casca, $\mathrm{em} \mathrm{m}^{3}$; ou carbono total no fuste estimado (madeira + casca), em kg; e

Yobs. = volume observado, com casca, $\mathrm{em} \mathrm{m}^{3}$; ou carbono total no fuste observado (madeira + casca), em $\mathrm{kg}$.

A determinação das idades técnicas de colheita (ITC's), considerando-se três classes de produtividade (alta, média e baixa), foi feita com base no máximo incremento médio mensal (IMM).

Para a realização das análises econômicas foi feita a conversão das estimativas de carbono para $\mathrm{CO}_{2}$ equivalente. Para isso, assumiu-se que uma tonelada de carbono equivaleria a 3,67 toneladas de $\mathrm{CO}_{2}$, ou que uma tonelada de $\mathrm{CO}_{2}$ equivaleria a 0,27 tonelada de carbono (FACE, 1994).

De posse das estimativas médias por hectare do estoque volumétrico e de carbono estocado no fuste (madeira + casca) na forma de $\mathrm{CO}_{2}$ equivalente, nas três classes de produtividade, realizou-se a análise econômica para dois cenários (Quadro 1). Considerouse não haver restrições de mercado quanto à comercialização da madeira e dos créditos de carbono.

A análise econômica dos cenários considerados foi realizada utilizando critérios econômicos que consideram a variação do capital ao longo do tempo, entre eles: Valor Anual Equivalente (VAE), Valor Presente Líquido (VPL), Taxa Interna de Retorno (TIR), Razão Beneficio/Custo (B/C) e Valor Esperado da Terra (VET) (SILVA et al., 2002).

O Valor Anual Equivalente (VAE) foi utilizado, também, para a definição da rotação econômica para cada cenário e condição de produtividade, isto é, das idades em que ocorreram os máximos retornos econômicos.

$\mathrm{Na}$ análise econômica foram considerados custos médios operacionais, por hectare, referentes às atividades envolvidas num projeto de reflorestamento e à taxa de desconto de $10 \%$ ao ano, conforme discriminado no Quadro 2.

Quadro 1 - Cenários para análise econômica Table 1 - Scenarios for economic analysis

\begin{tabular}{lc}
\hline Cenários & Descrição dos Produtos \\
\hline 1 - Sem CERs & Madeira \\
2 - Com CERs & Madeira + Certificados \\
& de Emissões Reduzidas \\
\hline
\end{tabular}


Quadro 2 - Custos operacionais

Table 2 - Operational costs

\begin{tabular}{lc}
\hline \multicolumn{1}{c}{ Itens } & Valores \\
\hline Custo de implantação $(\mathrm{R} \$ / \mathrm{ha})$ & $1.800,00$ \\
Custo de manutenção $-1^{\circ}$ ano $(\mathrm{R} \$ / \mathrm{ha})$ & 275,00 \\
Custo de manutenção $-2^{\circ}$ ano $(\mathrm{R} \$ / \mathrm{ha})$ & 260,00 \\
Custo de manutenção $-3^{\circ}$ ano $(\mathrm{R} \$ / \mathrm{ha})$ & 25,00 \\
Custo de manutenção - demais anos $(\mathrm{R} \$ / \mathrm{ha})$ & 25,00 \\
Custo de colheita e transporte $\left(\mathrm{R} \$ / \mathrm{m}^{3}\right)$ & 20,00 \\
Custo anual da terra $(\mathrm{R} \$ / \mathrm{ha})$ & 200,00 \\
\hline
\end{tabular}

Fonte: Empresas do setor, em Minas Gerais.

As receitas por hectare, considerando a venda da madeira e dos Certificados de Emissões Reduzidas (CERs), foram obtidas multiplicando-se as estimativas encontradas desses produtos pelos respectivos preços de mercado (Quadro 3). Na análise econômica, considerou-se que os CERs foram negociados no ano zero, ou seja, as receitas aconteceram no ano de implantação da cultura (pagamento antecipado).

Foram feitas análises de sensibilidade, considerando-se o critério econômico VPL, com o propósito de identificar pontos de nivelamento entre os diferentes usos, através da variação da taxa de desconto, dos custos de implantação e colheita e dos preços da madeira e dos CERs, em amplitude de $\pm 20 \%$. Da mesma forma, variaram-se o volume e o estoque de carbono até encontrar quais são as produtividades mínimas que tornam os projetos viáveis economicamente, de acordo com o critério VPL.

\section{RESULTADOS E DISCUSSÃO}

As equações ajustadas para estimar o volume total com casca e o carbono total dos fustes das árvores individuais de eucalipto e as respectivas medidas de precisão foram:

$$
\begin{aligned}
& \text { V Volume total com casca (Vcc) } \\
& L n V c c=-10,0708+1,8373 \operatorname{LnDAP}+1,0964 \mathrm{LnHt} \text { (5) } \\
& \mathrm{R}^{2}=99,52 \% \quad \mathrm{~S}_{\mathrm{y} . \mathrm{x} .}= \pm 0,0600 \ln \left(\mathrm{m}^{3}\right) \text { C.V. } \pm 7,10 \%
\end{aligned}
$$

Quadro 3 - Preços da madeira e carbono $\left(\mathrm{CO}_{2 \mathrm{eq}}\right)$ Table 3 - Wood and carbon $\left(\mathrm{CO}_{2 e q}\right)$ prices

\begin{tabular}{lcc}
\hline Item & \multicolumn{2}{c}{ Preço } \\
\cline { 2 - 3 } & $\left(\mathrm{R} \$ / \mathrm{m}^{3}\right)$ & $\left(\mathrm{R} \$ / \mathrm{t} \mathrm{CO}_{2 \text { eq }}\right)$ \\
\hline Madeira & 50,00 & - \\
$\mathrm{CO}_{2}$ seqüestrado & - & $6,00^{*}$ \\
\hline
\end{tabular}

*Valor sugerido na Bolsa de Chicago: US $\$ 2,72$, considerando US $\$ 1,00$ igual a $\mathrm{R} \$ 2,20$, em maio de 2006

Fonte: Empresas do setor (madeira) e Bolsa de Chicago $\left(\mathrm{CO}_{2}\right)$.

\section{- Carbono total no fuste (CF)}

$L n C F=-4,9220+1,8882 \operatorname{LnDAP}+1,1496 \mathrm{LnH} t$

$\mathrm{R}^{2}=98,55 \% \quad \mathrm{~S}_{\text {y.x. }}= \pm 0,0597 \ln (\mathrm{kg}) \quad$ C.V. $\pm 7,09 \%$

Os gráficos de distribuição dos resíduos porcentuais (Figura 1) mostram distribuição uniforme e sem tendência de super ou subestimação.

As equações ajustadas referentes ao modelo de crescimento e produção de Clutter (1983) foram:

\section{- Área basal}

$$
\begin{aligned}
\operatorname{LnB}_{2} & =\operatorname{Ln} B_{1} *\left(\frac{I_{1}}{I_{2}}\right)+3,3425 *\left(1-\frac{I_{1}}{I_{2}}\right)+0,0131 *\left(1-\frac{I_{1}}{I_{2}}\right) * S \\
\mathrm{R}^{2} & =96,91 \% \quad \mathrm{~S}_{\mathrm{y} . \mathrm{x} .}= \pm 0,0423 \ln \left(\mathrm{m}^{2} / \mathrm{ha}\right) \quad \mathrm{C} . \mathrm{V} . \pm 4,02 \%
\end{aligned}
$$
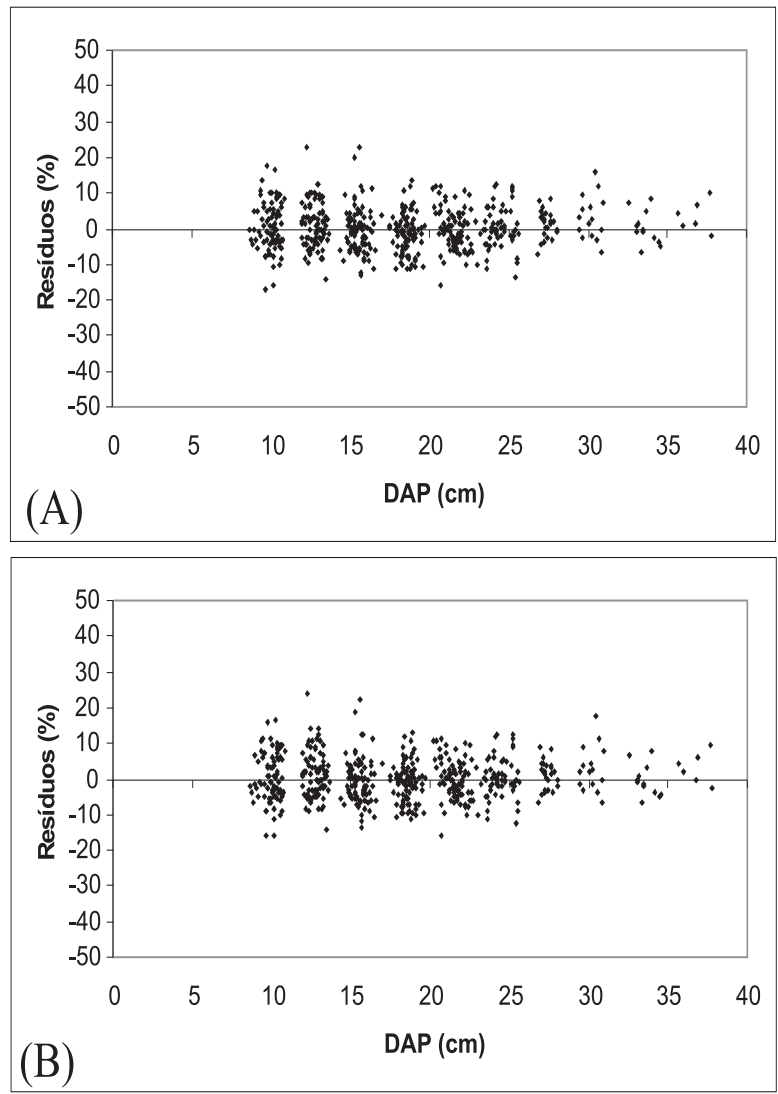

Figura 1 - Distribuição dos resíduos porcentuais das equações que estimam o volume total com casca (A) e o carbono total nos fustes das árvores de eucalipto(B).

Figure 1 -Distribution of the residuals of the equations that estimate the total volume with bark $(A)$ and total carbon in the eucalypt tree stems $(B)$. 


\section{Volume com casca}

$$
\operatorname{LnVcc}_{2}=1,5760-19,2699 *\left(\frac{1}{I_{2}}\right)+0,0287 * S+1,1249 * \operatorname{Ln} B_{2}
$$

$\mathrm{R}^{2}=98,73 \% \quad \mathrm{~S}_{\mathrm{y} . \mathrm{x} .}= \pm 0,0416 \ln \left(\mathrm{m}^{3} / \mathrm{ha}\right) \quad$ C.V. $\pm 4,18 \%$

\section{Carbono total no fuste}

$$
\begin{aligned}
\operatorname{LnCF}_{2} & =6,9747-20,6133 *\left(\frac{1}{I_{2}}\right)+0,0308 * S+1,1327 * \operatorname{LnB}_{2} \quad \text { (9) } \\
\mathrm{R}^{2} & =98,62 \% \quad \mathrm{~S}_{\mathrm{y} . \mathrm{x} .}= \pm 0,0445 \ln (\mathrm{Kg} / \mathrm{ha}) \quad \text { C.V. } \pm 4,48 \%
\end{aligned}
$$

As medidas de precisão indicam que as equações se ajustaram bem aos dados observados. Os gráficos de dispersão dos resíduos (Figura 2) mostram não haver tendência de super ou subestimação, tanto para o estoque em volume quanto para o estoque de carbono e da área basal por hectare pelas equações ajustadas.

As tabelas de produção referentes às equações 7 , 8 e 9, considerando-se três classes de produtividade ( $\mathrm{S}=20$, $\mathrm{S}=26$ e $\mathrm{S}=32$ ), são apresentadas nos Quadros 4 e 5.

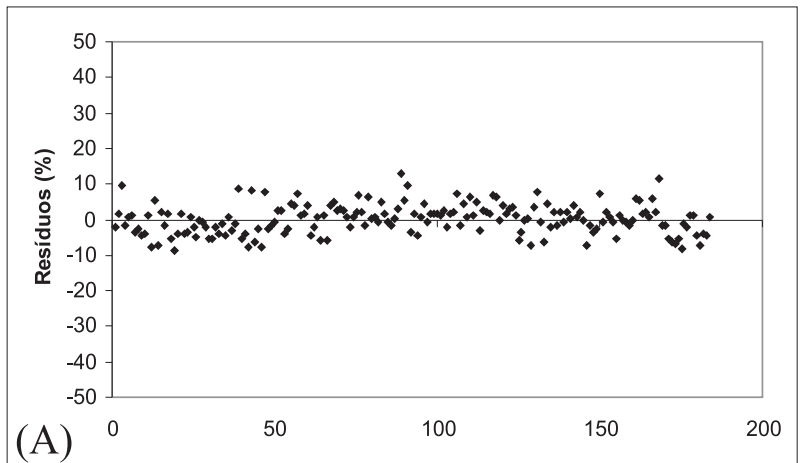

Tanto para o estoque volumétrico quanto para o estoque de carbono por hectare, houve diminuição da idade técnica de colheita (ITC) com o aumento da capacidade produtiva (Figura 3). Observou-se, ainda, diferença mínima das ITCs estimadas pelas equações que projetam o estoque volumétrico e o estoque de carbono por hectare. Isso se deveu ao uso de diferentes equações para estimar o volume e o carbono.

Semelhantemente às idades técnicas de colheita (ITCs), observou-se diminuição das rotações econômicas com o aumento da capacidade produtiva, tanto para o estoque volumétrico quanto para o estoque de carbono por hectare, nos dois cenários avaliados (Quadro 6).

Cabe ressaltar que as rotações econômicas foram maiores do que as idades técnicas de colheita (ITCs), para os projetos de baixa e média produtividade $(S=20$ e $S=26$ ), independentemente da inclusão ou não dos CERs. Para o projeto de maior produtividade, a rotação econômica foi praticamente igual a ITC.
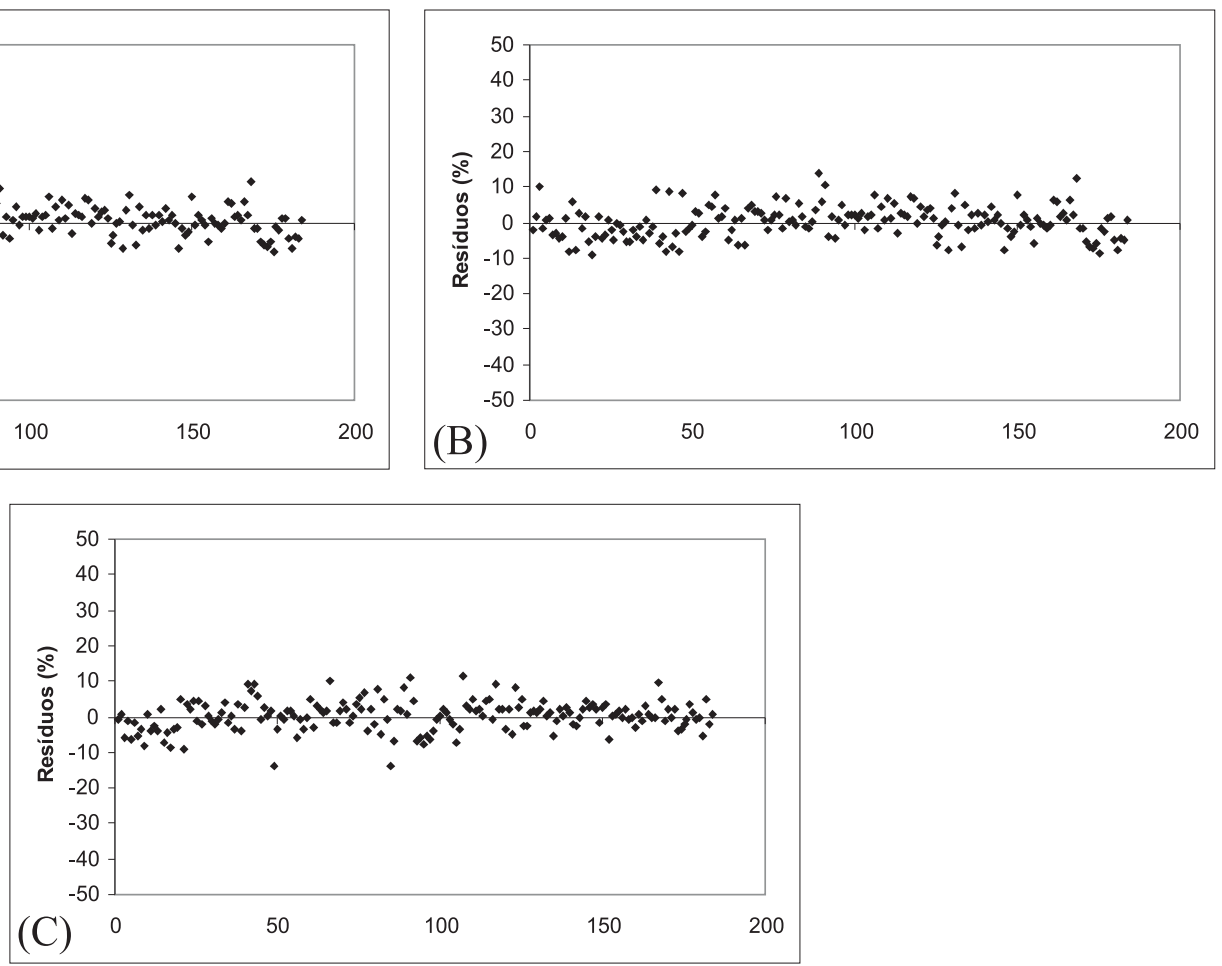

Figura 2 - Distribuição dos resíduos porcentuais das equações que estimam o estoque volumétrico (A) e de carbono (B) e a área basal (C) por hectare.

Figure 2 -Distribution of the percent residuals of the equations that estimate the volumetric $(A)$ and carbon $(B)$ tocks and basal area per hectare $(C)$. 
Quadro 4 - Tabela de produção para povoamentos de Eucalyptus grandis na região do Alto e Médio Rio Doce, Minas Gerais Table 4 - Yield table for stands of Eucalyptus grandis in the region of Rio Doce, Minas Gerais, Brazil

\begin{tabular}{|c|c|c|c|c|c|c|c|c|c|}
\hline \multirow{2}{*}{$\begin{array}{l}\text { Idade } \\
\text { (meses) }\end{array}$} & \multicolumn{3}{|c|}{$\mathrm{S}=20$} & \multicolumn{3}{|c|}{$S=26$} & \multicolumn{3}{|c|}{$\mathrm{S}=32$} \\
\hline & $\begin{array}{c}\mathrm{B} \\
\left(\mathrm{m}^{2} / \mathrm{ha}\right)\end{array}$ & $\begin{array}{c}\mathrm{Vcc} \\
\left(\mathrm{m}^{3} / \mathrm{ha}\right)\end{array}$ & $\begin{array}{c}\text { IMM } \\
\left(\mathrm{m}^{3} / \text { ha.mês }\right)\end{array}$ & $\begin{array}{c}\mathrm{B} \\
\left(\mathrm{m}^{2} / \mathrm{ha}\right)\end{array}$ & $\begin{array}{c}\mathrm{Vcc} \\
\left(\mathrm{m}^{3} / \mathrm{ha}\right)\end{array}$ & $\begin{array}{c}\text { IMM } \\
\left(\mathrm{m}^{3} / \text { ha.mês }\right)\end{array}$ & $\begin{array}{c}\mathrm{B} \\
\left(\mathrm{m}^{2} / \mathrm{ha}\right)\end{array}$ & $\begin{array}{c}\mathrm{Vcc} \\
\left(\mathrm{m}^{3} / \mathrm{ha}\right)\end{array}$ & $\begin{array}{c}\text { IMM } \\
\left(\mathrm{m}^{3} / \text { ha.mês }\right)\end{array}$ \\
\hline 32 & 5,42 & 31,51 & 0,98 & 10,69 & 80,31 & 2,51 & 13,97 & 129,05 & 4,03 \\
\hline 33 & 5,75 & 34,25 & 1,04 & 11,12 & 85,53 & 2,59 & 14,46 & 136,56 & 4,14 \\
\hline 34 & 6,07 & 37,06 & 1,09 & 11,54 & 90,76 & 2,67 & 14,93 & 144,03 & 4,24 \\
\hline 35 & 6,39 & 39,91 & 1,14 & 11,96 & 95,98 & 2,74 & 15,39 & 151,45 & 4,33 \\
\hline 36 & 6,71 & 42,80 & 1,19 & 12,37 & 101,19 & 2,81 & 15,84 & 158,81 & 4,41 \\
\hline 37 & 7,02 & 45,73 & 1,24 & 12,76 & 106,38 & 2,88 & 16,27 & 166,09 & 4,49 \\
\hline 38 & 7,34 & 48,69 & 1,28 & 13,15 & 111,54 & 2,94 & 16,69 & 173,31 & 4,56 \\
\hline 39 & 7,65 & 51,67 & 1,32 & 13,53 & 116,66 & 2,99 & 17,10 & 180,44 & 4,63 \\
\hline 40 & 7,95 & 54,68 & 1,37 & 13,90 & 121,75 & 3,04 & 17,50 & 187,48 & 4,69 \\
\hline 41 & 8,25 & 57,70 & 1,41 & 14,26 & 126,79 & 3,09 & 17,89 & 194,44 & 4,74 \\
\hline 42 & 8,55 & 60,73 & 1,45 & 14,61 & 131,79 & 3,14 & 18,27 & 201,31 & 4,79 \\
\hline 43 & 8,85 & 63,77 & 1,48 & 14,96 & 136,74 & 3,18 & 18,63 & 208,08 & 4,84 \\
\hline 44 & 9,14 & 66,81 & 1,52 & 15,29 & 141,64 & 3,22 & 18,99 & 214,76 & 4,88 \\
\hline 45 & 9,43 & 69,85 & 1,55 & 15,62 & 146,48 & 3,26 & 19,34 & 221,34 & 4,92 \\
\hline 46 & 9,71 & 72,89 & 1,58 & 15,94 & 151,27 & 3,29 & 19,68 & 227,82 & 4,95 \\
\hline 47 & 9,99 & 75,92 & 1,62 & 16,25 & 156,00 & 3,32 & 20,01 & 234,21 & 4,98 \\
\hline 48 & 10,26 & 78,95 & 1,64 & 16,56 & 160,68 & 3,35 & 20,33 & 240,49 & 5,01 \\
\hline 49 & 10,53 & 81,97 & 1,67 & 16,86 & 165,29 & 3,37 & 20,65 & 246,68 & 5,03 \\
\hline 50 & 10,80 & 84,97 & 1,70 & 17,15 & 169,84 & 3,40 & 20,95 & 252,77 & 5,06 \\
\hline 51 & 11,06 & 87,96 & 1,72 & 17,44 & 174,34 & 3,42 & 21,25 & 258,77 & 5,07 \\
\hline 52 & 11,32 & 90,93 & 1,75 & 17,72 & 178,77 & 3,44 & 21,54 & 264,66 & 5,09 \\
\hline 53 & 11,58 & 93,89 & 1,77 & 17,99 & 183,14 & 3,46 & 21,82 & 270,47 & 5,10 \\
\hline 54 & 11,83 & 96,83 & 1,79 & 18,25 & 187,45 & 3,47 & 22,10 & 276,17 & 5,11 \\
\hline 55 & 12,07 & 99,74 & 1,81 & 18,51 & 191,70 & 3,49 & 22,37 & 281,79 & 5,12 \\
\hline 56 & 12,32 & 102,64 & 1,83 & 18,77 & 195,89 & 3,50 & 22,63 & 287,31 & 5,13 \\
\hline 57 & 12,56 & 105,51 & 1,85 & 19,02 & 200,02 & 3,51 & 22,89 & 292,74 & 5,14 \\
\hline 58 & 12,79 & 108,37 & 1,87 & 19,26 & 204,09 & 3,52 & 23,14 & 298,08 & 5,14 \\
\hline 59 & 13,02 & 111,20 & 1,88 & 19,50 & 208,10 & 3,53 & 23,38 & 303,33 & 5,14 \\
\hline 60 & 13,25 & 114,00 & 1,90 & 19,73 & 212,05 & 3,53 & $\underline{23,62}$ & $\underline{308,49}$ & $\underline{5,14}$ \\
\hline 61 & 13,47 & 116,78 & 1,91 & 19,96 & 215,94 & 3,54 & 23,86 & 313,57 & 5,14 \\
\hline 62 & 13,69 & 119,53 & 1,93 & 20,18 & 219,78 & 3,54 & 24,08 & 318,56 & 5,14 \\
\hline 63 & 13,91 & 122,26 & 1,94 & 20,40 & 223,56 & 3,55 & 24,31 & 323,47 & 5,13 \\
\hline 64 & 14,12 & 124,97 & 1,95 & 20,62 & 227,28 & 3,55 & 24,53 & 328,30 & 5,13 \\
\hline 65 & 14,33 & 127,64 & 1,96 & 20,83 & 230,94 & 3,55 & 24,74 & 333,05 & 5,12 \\
\hline 66 & 14,54 & 130,29 & 1,97 & 21,03 & 234,56 & 3,55 & 24,95 & 337,73 & 5,12 \\
\hline 67 & 14,74 & 132,92 & 1,98 & $\underline{21,23}$ & $\underline{238,11}$ & $\underline{\mathbf{3 , 5 5}}$ & 25,15 & 342,32 & 5,11 \\
\hline 68 & 14,94 & 135,52 & 1,99 & 21,43 & 241,62 & 3,55 & 25,35 & 346,84 & 5,10 \\
\hline 69 & 15,14 & 138,09 & 2,00 & 21,62 & 245,07 & 3,55 & 25,55 & 351,29 & 5,09 \\
\hline 70 & 15,33 & 140,63 & 2,01 & 21,81 & 248,48 & 3,55 & 25,74 & 355,66 & 5,08 \\
\hline 71 & 15,52 & 143,15 & 2,02 & 22,00 & 251,83 & 3,55 & 25,92 & 359,96 & 5,07 \\
\hline 72 & 15,71 & 145,64 & 2,02 & 22,18 & 255,13 & 3,54 & 26,11 & 364,20 & 5,06 \\
\hline 73 & 15,89 & 148,10 & 2,03 & 22,36 & 258,38 & 3,54 & 26,29 & 368,36 & 5,05 \\
\hline 74 & 16,07 & 150,54 & 2,03 & 22,53 & 261,58 & 3,53 & 26,46 & 372,46 & 5,03 \\
\hline 75 & 16,25 & 152,95 & 2,04 & 22,70 & 264,74 & 3,53 & 26,63 & 376,49 & 5,02 \\
\hline
\end{tabular}


Quadro 4-Cont

Table 4 - Cont.

\begin{tabular}{|c|c|c|c|c|c|c|c|c|c|}
\hline \multirow{2}{*}{$\begin{array}{l}\text { Idade } \\
\text { (meses) }\end{array}$} & \multicolumn{3}{|c|}{$S=20$} & \multicolumn{3}{|c|}{$S=26$} & \multicolumn{3}{|c|}{$S=32$} \\
\hline & $\begin{array}{c}\text { B } \\
\left(\mathrm{m}^{2} / \mathrm{ha}\right)\end{array}$ & $\begin{array}{c}\mathrm{Vcc} \\
\left(\mathrm{m}^{3} / \mathrm{ha}\right)\end{array}$ & $\begin{array}{c}\text { IMM } \\
\left(\mathrm{m}^{3} / \text { ha.mês }\right)\end{array}$ & $\begin{array}{c}\text { B } \\
\left(\mathrm{m}^{2} / \mathrm{ha}\right)\end{array}$ & $\begin{array}{c}\mathrm{Vcc} \\
\left(\mathrm{m}^{3} / \mathrm{ha}\right)\end{array}$ & $\begin{array}{c}\text { IMM } \\
\left(\mathrm{m}^{3} / \text { ha.mês }\right)\end{array}$ & $\begin{array}{c}\text { B } \\
\left(\mathrm{m}^{2} / \mathrm{ha}\right)\end{array}$ & $\begin{array}{c}\mathrm{Vcc} \\
\left(\mathrm{m}^{3} / \mathrm{ha}\right)\end{array}$ & $\begin{array}{c}\text { IMM } \\
\left(\mathrm{m}^{3} / \text { ha.mês }\right)\end{array}$ \\
\hline 76 & 16,42 & 155,33 & 2,04 & 22,87 & 267,85 & 3,52 & 26,80 & 380,46 & 5,01 \\
\hline 77 & 16,60 & 157,69 & 2,05 & 23,04 & 270,92 & 3,52 & 26,97 & 384,36 & 4,99 \\
\hline 78 & 16,77 & 160,02 & 2,05 & 23,20 & 273,94 & 3,51 & 27,13 & 388,21 & 4,98 \\
\hline 79 & 16,94 & 162,33 & 2,05 & 23,36 & 276,91 & 3,51 & 27,29 & 391,99 & 4,96 \\
\hline 80 & 17,10 & 164,61 & 2,06 & 23,51 & 279,85 & 3,50 & 27,45 & 395,71 & 4,95 \\
\hline 81 & 17,26 & 166,87 & 2,06 & 23,67 & 282,74 & 3,49 & 27,60 & 399,38 & 4,93 \\
\hline 82 & 17,42 & 169,10 & 2,06 & 23,82 & 285,58 & 3,48 & 27,75 & 402,99 & 4,91 \\
\hline 83 & 17,58 & 171,30 & 2,06 & 23,96 & 288,39 & 3,47 & 27,90 & 406,54 & 4,90 \\
\hline 84 & 17,74 & 173,48 & 2,07 & 24,11 & 291,16 & 3,47 & 28,04 & 410,04 & 4,88 \\
\hline 85 & 17,89 & 175,64 & 2,07 & 24,25 & 293,89 & 3,46 & 28,18 & 413,49 & 4,86 \\
\hline 86 & 18,04 & 177,77 & 2,07 & 24,39 & 296,58 & 3,45 & 28,32 & 416,88 & 4,85 \\
\hline 87 & 18,19 & 179,88 & 2,07 & 24,53 & 299,23 & 3,44 & 28,46 & 420,23 & 4,83 \\
\hline 88 & $\underline{18,33}$ & 181,96 & $\underline{\mathbf{2}, 07}$ & 24,66 & 301,84 & 3,43 & 28,59 & 423,52 & 4,81 \\
\hline 89 & $\overline{18,48}$ & $\overline{184,02}$ & 2,07 & 24,80 & 304,42 & 3,42 & 28,72 & 426,76 & 4,80 \\
\hline 90 & 18,62 & 186,06 & 2,07 & 24,93 & 306,96 & 3,41 & 28,85 & 429,96 & 4,78 \\
\hline 91 & 18,76 & 188,07 & 2,07 & 25,05 & 309,46 & 3,40 & 28,98 & 433,11 & 4,76 \\
\hline 92 & 18,90 & 190,06 & 2,07 & 25,18 & 311,93 & 3,39 & 29,10 & 436,21 & 4,74 \\
\hline 93 & 19,03 & 192,03 & 2,06 & 25,31 & 314,37 & 3,38 & 29,23 & 439,27 & 4,72 \\
\hline 94 & 19,17 & 193,98 & 2,06 & 25,43 & 316,78 & 3,37 & 29,35 & 442,28 & 4,71 \\
\hline 95 & 19,30 & 195,90 & 2,06 & 25,55 & 319,15 & 3,36 & 29,47 & 445,25 & 4,69 \\
\hline 96 & 19,43 & 197,81 & 2,06 & 25,67 & 321,48 & 3,35 & 29,58 & 448,18 & 4,67 \\
\hline
\end{tabular}

$\mathrm{B}=$ área basal por hectare, $\mathrm{Vcc}=$ volume total com casca por hectare e IMM = incremento mensal médio; B = basal area per hectare, $\mathrm{Vcc}=$ total volume outside bark per hectare and IMM $=$ mean monthly increment.

Quadro 5 - Tabela de produção para povoamentos de Eucalyptus grandis na região do Alto e Médio Rio Doce, Minas Gerais Table 5 - Yield table for stands of Eucalyptus grandis in the region of Rio Doce, Minas Gerais, Brazil

\begin{tabular}{|c|c|c|c|c|c|c|c|c|c|}
\hline \multirow{2}{*}{$\begin{array}{l}\text { Idade } \\
\text { (meses) }\end{array}$} & \multicolumn{3}{|c|}{$S=20$} & \multicolumn{3}{|c|}{$S=26$} & \multicolumn{3}{|c|}{$\mathrm{S}=32$} \\
\hline & $\begin{array}{c}\mathrm{B} \\
\left(\mathrm{m}^{2} / \mathrm{ha}\right)\end{array}$ & $\begin{array}{c}\mathrm{CF} \\
(\mathrm{t} / \mathrm{ha})\end{array}$ & $\begin{array}{c}\text { IMM } \\
\text { (t/ha.mês) }\end{array}$ & $\begin{array}{c}\mathrm{B} \\
\left(\mathrm{m}^{2} / \mathrm{ha}\right)\end{array}$ & $\begin{array}{c}\mathrm{CF} \\
(\mathrm{t} / \mathrm{ha})\end{array}$ & $\begin{array}{c}\text { IMM } \\
\text { (t/ha.mês) }\end{array}$ & $\begin{array}{c}\mathrm{B} \\
\left(\mathrm{m}^{2} / \mathrm{ha}\right)\end{array}$ & $\begin{array}{c}\mathrm{CF} \\
\text { (t/ha) }\end{array}$ & $\begin{array}{c}\text { IMM } \\
\text { (t/ha.mês) }\end{array}$ \\
\hline 32 & 5,42 & 7,05 & 0,22 & 10,69 & 18,28 & 0,57 & 13,97 & 29,80 & 0,93 \\
\hline 33 & 5,75 & 7,68 & 0,23 & 11,12 & 19,50 & 0,59 & 14,46 & 31,58 & 0,96 \\
\hline 34 & 6,07 & 8,32 & 0,24 & 11,54 & 20,72 & 0,61 & 14,93 & 33,36 & 0,98 \\
\hline 35 & 6,39 & 8,97 & 0,26 & 11,96 & 21,95 & 0,63 & 15,39 & 35,12 & 1,00 \\
\hline 36 & 6,71 & 9,63 & 0,27 & 12,37 & 23,17 & 0,64 & 15,84 & 36,88 & 1,02 \\
\hline 37 & 7,02 & 10,31 & 0,28 & 12,76 & 24,39 & 0,66 & 16,27 & 38,61 & 1,04 \\
\hline 38 & 7,34 & 10,99 & 0,29 & 13,15 & 25,60 & 0,67 & 16,69 & 40,34 & 1,06 \\
\hline 39 & 7,65 & 11,68 & 0,30 & 13,53 & 26,81 & 0,69 & 17,10 & 42,04 & 1,08 \\
\hline 40 & 7,95 & 12,37 & 0,31 & 13,90 & 28,01 & 0,70 & 17,50 & 43,73 & 1,09 \\
\hline 41 & 8,25 & 13,07 & 0,32 & 14,26 & 29,20 & 0,71 & 17,89 & 45,40 & 1,11 \\
\hline 42 & 8,55 & 13,77 & 0,33 & 14,61 & 30,38 & 0,72 & 18,27 & 47,05 & 1,12 \\
\hline 43 & 8,85 & 14,47 & 0,34 & 14,96 & 31,55 & 0,73 & 18,63 & 48,67 & 1,13 \\
\hline 44 & 9,14 & 15,18 & 0,34 & 15,29 & 32,71 & 0,74 & 18,99 & 50,28 & 1,14 \\
\hline 45 & 9,43 & 15,88 & 0,35 & 15,62 & 33,85 & 0,75 & 19,34 & 51,86 & 1,15 \\
\hline 46 & 9,71 & 16,59 & 0,36 & 15,94 & 34,99 & 0,76 & 19,68 & 53,42 & 1,16 \\
\hline 47 & 9,99 & 17,30 & 0,37 & 16,25 & 36,11 & 0,77 & 20,01 & 54,96 & 1,17 \\
\hline 48 & 10,26 & 18,00 & 0,37 & 16,56 & 37,22 & 0,78 & 20,33 & 56,48 & 1,18 \\
\hline 49 & 10,53 & 18,70 & 0,38 & 16,86 & 38,31 & 0,78 & 20,65 & 57,97 & 1,18 \\
\hline
\end{tabular}




\begin{tabular}{|c|c|c|c|c|c|c|c|c|c|}
\hline \multirow{2}{*}{$\begin{array}{l}\text { Idade } \\
\text { (meses) }\end{array}$} & \multicolumn{3}{|c|}{$\mathrm{S}=20$} & \multicolumn{3}{|c|}{$\mathrm{S}=26$} & \multicolumn{3}{|c|}{$\mathrm{S}=32$} \\
\hline & $\begin{array}{c}\text { B } \\
\left(\mathrm{m}^{2} / \mathrm{ha}\right) \\
\end{array}$ & $\begin{array}{c}\mathrm{CF} \\
(\mathrm{t} / \mathrm{ha})\end{array}$ & $\begin{array}{c}\text { IMM } \\
\text { (t/ha.mês) } \\
\end{array}$ & $\begin{array}{c}\text { B } \\
\left(\mathrm{m}^{2} / \mathrm{ha}\right) \\
\end{array}$ & $\begin{array}{c}\mathrm{CF} \\
(\mathrm{t} / \mathrm{ha})\end{array}$ & $\begin{array}{c}\text { IMM } \\
\text { (t/ha.mês) } \\
\end{array}$ & $\begin{array}{c}\text { B } \\
\left(\mathrm{m}^{2} / \mathrm{ha}\right) \\
\end{array}$ & $\begin{array}{c}\mathrm{CF} \\
(\mathrm{t} / \mathrm{ha})\end{array}$ & $\begin{array}{c}\text { IMM } \\
\text { (t/ha.mês) }\end{array}$ \\
\hline 50 & 10,80 & 19,40 & 0,39 & 17,15 & 39,40 & 0,79 & 20,95 & 59,44 & 1,19 \\
\hline 51 & 11,06 & 20,10 & 0,39 & 17,44 & 40,47 & 0,79 & 21,25 & 60,89 & 1,19 \\
\hline 52 & 11,32 & 20,79 & 0,40 & 17,72 & 41,52 & 0,80 & 21,54 & 62,32 & 1,20 \\
\hline 53 & 11,58 & 21,48 & 0,41 & 17,99 & 42,56 & 0,80 & 21,82 & 63,72 & 1,20 \\
\hline 54 & 11,83 & 22,17 & 0,41 & 18,25 & 43,59 & 0,81 & 22,10 & 65,10 & 1,21 \\
\hline 55 & 12,07 & 22,85 & 0,42 & 18,51 & 44,60 & 0,81 & 22,37 & 66,46 & 1,21 \\
\hline 56 & 12,32 & 23,53 & 0,42 & 18,77 & 45,60 & 0,81 & 22,63 & 67,80 & 1,21 \\
\hline 57 & 12,56 & 24,20 & 0,42 & 19,02 & 46,59 & 0,82 & 22,89 & 69,11 & 1,21 \\
\hline 58 & 12,79 & 24,87 & 0,43 & 19,26 & 47,56 & 0,82 & 23,14 & 70,41 & 1,21 \\
\hline 59 & 13,02 & 25,53 & 0,43 & 19,50 & 48,52 & 0,82 & 23,38 & 71,68 & 1,21 \\
\hline 60 & 13,25 & 26,19 & 0,44 & 19,73 & 49,46 & 0,82 & 23,62 & 72,94 & 1,22 \\
\hline 61 & 13,47 & 26,84 & 0,44 & 19,96 & 50,39 & 0,83 & $\underline{23,86}$ & $\underline{74,17}$ & $\underline{1,22}$ \\
\hline 62 & 13,69 & 27,49 & 0,44 & 20,18 & 51,31 & 0,83 & 24,08 & 75,38 & 1,22 \\
\hline 63 & 13,91 & 28,13 & 0,45 & 20,40 & 52,21 & 0,83 & 24,31 & 76,58 & 1,22 \\
\hline 64 & 14,12 & 28,76 & 0,45 & 20,62 & 53,11 & 0,83 & 24,53 & 77,75 & 1,21 \\
\hline 65 & 14,33 & 29,39 & 0,45 & 20,83 & 53,98 & 0,83 & 24,74 & 78,91 & 1,21 \\
\hline 66 & 14,54 & 30,01 & 0,45 & 21,03 & 54,85 & 0,83 & 24,95 & 80,05 & 1,21 \\
\hline 67 & 14,74 & 30,63 & 0,46 & 21,23 & 55,70 & 0,83 & 25,15 & 81,17 & 1,21 \\
\hline 68 & 14,94 & 31,24 & 0,46 & $\underline{21,43}$ & $\underline{56,54}$ & $\underline{0,83}$ & 25,35 & 82,27 & 1,21 \\
\hline 69 & 15,14 & 31,85 & 0,46 & 21,62 & 57,37 & 0,83 & 25,55 & 83,35 & 1,21 \\
\hline 70 & 15,33 & 32,45 & 0,46 & 21,81 & 58,19 & 0,83 & 25,74 & 84,42 & 1,21 \\
\hline 71 & 15,52 & 33,04 & 0,47 & 22,00 & 58,99 & 0,83 & 25,92 & 85,47 & 1,20 \\
\hline 72 & 15,71 & 33,63 & 0,47 & 22,18 & 59,79 & 0,83 & 26,11 & 86,50 & 1,20 \\
\hline 73 & 15,89 & 34,21 & 0,47 & 22,36 & 60,57 & 0,83 & 26,29 & 87,51 & 1,20 \\
\hline 74 & 16,07 & 34,78 & 0,47 & 22,53 & 61,34 & 0,83 & 26,46 & 88,51 & 1,20 \\
\hline 75 & 16,25 & 35,35 & 0,47 & 22,70 & 62,10 & 0,83 & 26,63 & 89,50 & 1,19 \\
\hline 76 & 16,42 & 35,91 & 0,47 & 22,87 & 62,85 & 0,83 & 26,80 & 90,47 & 1,19 \\
\hline 77 & 16,60 & 36,47 & 0,47 & 23,04 & 63,58 & 0,83 & 26,97 & 91,42 & 1,19 \\
\hline 78 & 16,77 & 37,02 & 0,47 & 23,20 & 64,31 & 0,82 & 27,13 & 92,36 & 1,18 \\
\hline 79 & 16,94 & 37,57 & 0,48 & 23,36 & 65,03 & 0,82 & 27,29 & 93,29 & 1,18 \\
\hline 80 & 17,10 & 38,10 & 0,48 & 23,51 & 65,73 & 0,82 & 27,45 & 94,20 & 1,18 \\
\hline 81 & 17,26 & 38,64 & 0,48 & 23,67 & 66,43 & 0,82 & 27,60 & 95,09 & 1,17 \\
\hline 82 & 17,42 & 39,16 & 0,48 & 23,82 & 67,11 & 0,82 & 27,75 & 95,98 & 1,17 \\
\hline 83 & 17,58 & 39,69 & 0,48 & 23,96 & 67,79 & 0,82 & 27,90 & 96,84 & 1,17 \\
\hline 84 & 17,74 & 40,20 & 0,48 & 24,11 & 68,46 & 0,81 & 28,04 & 97,70 & 1,16 \\
\hline 85 & 17,89 & 40,71 & 0,48 & 24,25 & 69,11 & 0,81 & 28,18 & 98,54 & 1,16 \\
\hline 86 & 18,04 & 41,21 & 0,48 & 24,39 & 69,76 & 0,81 & 28,32 & 99,38 & 1,16 \\
\hline 87 & 18,19 & 41,71 & 0,48 & 24,53 & 70,40 & 0,81 & 28,46 & 100,19 & 1,15 \\
\hline 88 & 18,33 & 42,21 & 0,48 & 24,66 & 71,03 & 0,81 & 28,59 & 101,00 & 1,15 \\
\hline 89 & 18,48 & 42,69 & 0,48 & 24,80 & 71,65 & 0,81 & 28,72 & 101,80 & 1,14 \\
\hline 90 & $\underline{18,62}$ & $\underline{43,18}$ & $\underline{0,48}$ & 24,93 & 72,27 & 0,80 & 28,85 & 102,58 & 1,14 \\
\hline 91 & 18,76 & $\overline{43,65}$ & $\overline{0,48}$ & 25,05 & 72,87 & 0,80 & 28,98 & 103,35 & 1,14 \\
\hline 92 & 18,90 & 44,13 & 0,48 & 25,18 & 73,47 & 0,80 & 29,10 & 104,11 & 1,13 \\
\hline 93 & 19,03 & 44,59 & 0,48 & 25,31 & 74,06 & 0,80 & 29,23 & 104,86 & 1,13 \\
\hline 94 & 19,17 & 45,05 & 0,48 & 25,43 & 74,64 & 0,79 & 29,35 & 105,60 & 1,12 \\
\hline 95 & 19,30 & 45,51 & 0,48 & 25,55 & 75,21 & 0,79 & 29,47 & 106,33 & 1,12 \\
\hline 96 & 19,43 & 45,96 & 0,48 & 25,67 & 75,78 & 0,79 & 29,58 & 107,05 & 1,12 \\
\hline
\end{tabular}

$\mathrm{B}=$ área basal por hectare, $\mathrm{CF}=$ estoque total de carbono no fuste por hectare e IMM = incremento médio mensal; $\mathrm{B}=$ basal area per hectare, $\mathrm{CF}=$ total stock of the carbon per hectare and $\mathrm{IMM}=$ mean monthly increment.

R. Árvore, Viçosa-MG, v.32, n.6, p.979-992, 2008 

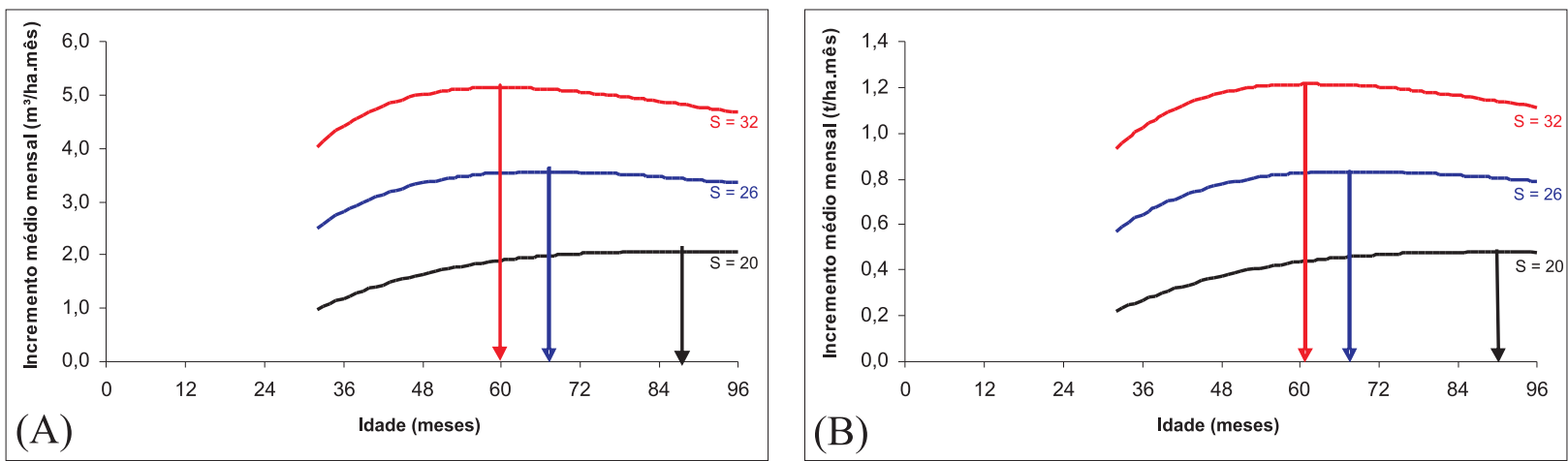

Figura 3 - Curvas de incrementos médios mensais para o volume total com casca (A) e para o carbono total por hectare (B), considerando-se as três classes de produtividade.

Figure 3 - Mean monthly increments for the total volume with bark (A) and for total carbon (B) per hectare, considering the three productivity classes.

Quadro 6 - Rotação econômica, volume total com casca por hectare (Vcc) e estoque de $\mathrm{CO}_{2}$ equivalente por hectare, para os dois cenários avaliados

Table 6 - Economic rotation, total volume per hectare (Vcc), stock of $\mathrm{CO}_{2}$ equivalent per hectare, for the two scenarios evaluated

\begin{tabular}{|c|c|c|c|}
\hline \multicolumn{4}{|c|}{ Cenário $1-$ Somente madeira } \\
\hline Classe de produtividade & Rotação econômi & & $\operatorname{Vcc}\left(\mathrm{m}^{3} / \mathrm{ha}\right)$ \\
\hline $\mathrm{S}=20$ & 8 & & 197,84 \\
\hline$S=26$ & 6 & & 255,16 \\
\hline $\mathrm{S}=32$ & 5 & & 308,49 \\
\hline \multicolumn{4}{|c|}{ Cenário 2 - Madeira + CERs } \\
\hline Classe de produtividade & Rotação econômica (anos) & $\operatorname{Vcc}\left(\mathrm{m}^{3} / \mathrm{ha}\right)$ & $\mathrm{CO}_{2(\text { eq })}\left(\mathrm{tCO}_{2} / \mathrm{ha}\right)$ \\
\hline $\mathrm{S}=20$ & 9 & 219,09 & 187,22 \\
\hline$S=26$ & 6 & 255,16 & 219,44 \\
\hline $\mathrm{S}=32$ & 5 & 308,49 & 267,68 \\
\hline
\end{tabular}

De acordo com os critérios econômicos, projetos em locais de média e alta produtividades ( $\mathrm{S}=26$ e $\mathrm{S}=32)$, foram considerados viáveis economicamente para os cenários sem e com os CERs (Quadro 7). Em local de baixa produtividade $(S=20)$, o projeto foi considerado inviável economicamente no cenário sem os CERs e viável economicamente no cenário com os CERs. Dessa forma, verificou-se que a inclusão dos créditos de carbono contribui para viabilidade financeira de projetos florestais em locais de baixa produtividade.

Comparando os cenários sem e com os CERs, em termos de Valor Anual Equivalente (VAE) (Quadro 7 e Figura 4), observou-se que o local de alta produtividade $(\mathrm{S}=32)$ foi o mais atrativo economicamente, com receitas anuais de R \$693,43/ha (sem os CERs) e R $\$ 1.117,11$ / ha (com a inclusão dos CERs). O local de média produtividade $(\mathrm{S}=26)$ também se mostrou viável, com aumento da receita anual de $\mathrm{R} \$ 247,07 /$ ha para $\mathrm{R} \$ 549,38$ / ha, após a inclusão dos CERs (aumento de 122,3\%).
Esse aumento significativo do VAE se deve ao fato de as receitas auferidas pelos CERs terem sido inseridas na implantação do projeto, não sofrendo, portanto, descapitalização.

A análise de sensibilidade, considerando o critério VPL, foi realizada para os dois cenários estudados, submetendo a taxa de desconto, os preços da madeira e os CERs e os custos a variações de seus valores nominais em $\pm 20 \%$.

De acordo com o Quadro 8 e a Figura 5A, no local de baixa produtividade ( $S=20$ ) o decréscimo de $20 \%$ na taxa de desconto, no custo de implantação ou no custo de colheita, não foi suficiente para tornar o projeto viável economicamente. Mas o aumento em $20 \%$ no preço da madeira tornou-o viável economicamente. Mantendo-se constante a taxa de desconto em $10 \%$ a.a. e os demais custos, o preço da madeira deveria ser superior a $\mathrm{R} \$ 57,55 / \mathrm{m}^{3}$ para manter o projeto viável economicamente, ou seja, um aumento de 15,10\% em relação ao preço inicial de $\mathrm{R} \$ 50,00 / \mathrm{m}^{3}$.

R. Árvore, Viçosa-MG, v.32, n.6, p.979-992, 2008 
Quadro 7 - Avaliação econômica dos dois cenários avaliados Table 7 - Economic evaluation for the two scenarios

\begin{tabular}{ccccc}
\hline Critério de comparação & Cenário & \multicolumn{3}{c}{ Classes de produtividade } \\
\cline { 3 - 5 } & & $\mathrm{S}=20$ & $\mathrm{~S}=26$ & $\mathrm{~S}=32$ \\
\hline VAE (R\$/ha.ano) & sem/CERs & $-130,55$ & 247,07 & 693,43 \\
VPL (R\$/ha) & com/CERs & 60,79 & 549,38 & $1.117,11$ \\
& sem/CERs & $-696,48$ & $1.076,06$ & $2.628,65$ \\
TIR (\% a.a.) & com/CERs & 350,12 & $2.392,71$ & $4.234,74$ \\
& sem/CERs & 7,57 & 14,27 & 21,36 \\
B/C & com/CERs & 11,30 & 21,75 & 34,05 \\
& sem/CERs & 0,869 & 1,176 & 1,378 \\
VET (R $\$$ /ha) & com/CERs & 1,065 & 1,391 & 1,609 \\
& sem/CERs & 694,49 & $4.470,72$ & $8.934,31$ \\
& com/CERs & $2.607,94$ & $7.493,85$ & $13.171,13$ \\
\hline
\end{tabular}

* Taxa de desconto $=10 \%$ a.a.

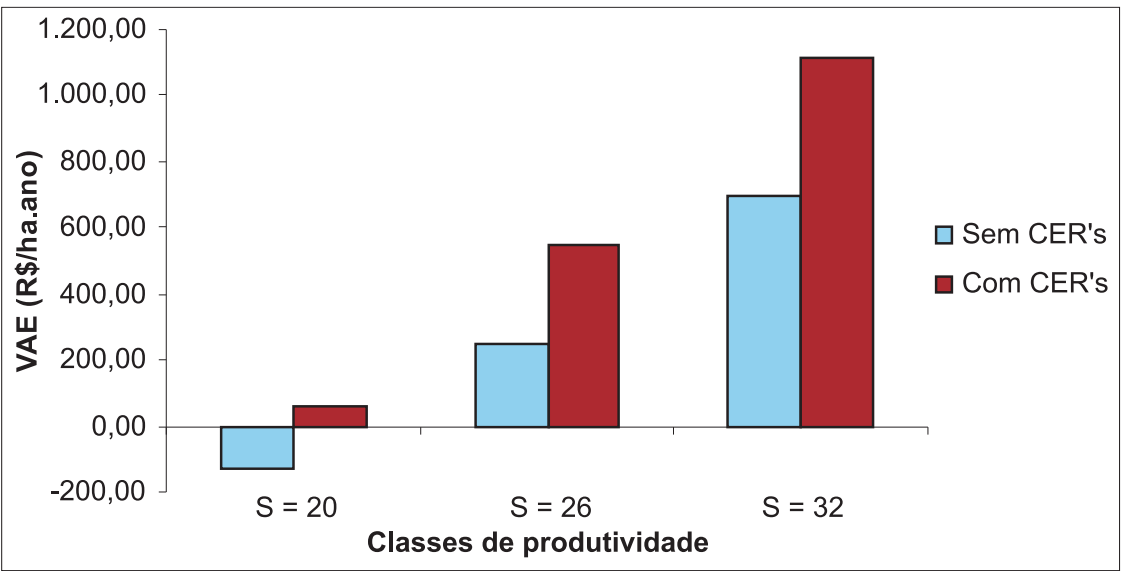

Figura 4 - Valor Anual Equivalente (VAE), em R \$/ha.ano, das três classes de produtividade, considerando-se os dois cenários avaliados, e taxa de desconto igual a $10 \%$ a.a.

Figure 4 - Equivalent Annual Value (VAE), in $R \$$ /ha.year, for the three productivity classes, considering the two scenarios and discount rate of $10 \%$ per year.

Quadro 8 - Análise de sensibilidade sem considerar os Certificados de Emissões Reduzidas (CERs) Table 8 -Sensitivity analysis without considering the Reduced Emission Certificates (RECs)

\begin{tabular}{|c|c|c|c|c|}
\hline \multirow[t]{2}{*}{ Classe de produtividade } & \multirow[t]{2}{*}{ Variável } & \multicolumn{3}{|c|}{ VPL } \\
\hline & & $-20 \%$ & 0 & $20 \%$ \\
\hline \multirow[t]{4}{*}{$S=20$} & Taxa de desconto & $-134,13$ & $-696,48$ & $-1.172,15$ \\
\hline & Preço da madeira & $-1.619,40$ & $-696,48$ & 226,44 \\
\hline & Custo de implantação & $-336,48$ & $-696,48$ & $-1.056,48$ \\
\hline & Custo de colheita & $-327,31$ & $-696,48$ & $-1.065,65$ \\
\hline \multirow[t]{4}{*}{$S=26$} & Taxa de desconto & $1.690,98$ & $1.076,06$ & 535,77 \\
\hline & Preço da madeira & $-364,23$ & $1.076,06$ & $2.516,35$ \\
\hline & Custo de implantação & $1.436,06$ & $1.076,06$ & 716,06 \\
\hline & Custo de colheita & $1.652,18$ & $1.076,06$ & 499,95 \\
\hline \multirow[t]{4}{*}{$\mathrm{S}=32$} & Taxa de desconto & $3.282,42$ & $2.628,65$ & $2.043,31$ \\
\hline & Preço da madeira & 713,17 & $2.628,65$ & $4.544,14$ \\
\hline & Custo de implantação & $2.988,65$ & $2.628,65$ & $2.268,65$ \\
\hline & Custo de colheita & $3.394,84$ & $2.628,65$ & $1.862,46$ \\
\hline
\end{tabular}

R. Árvore, Viçosa-MG, v.32, n.6, p.979-992, 2008 

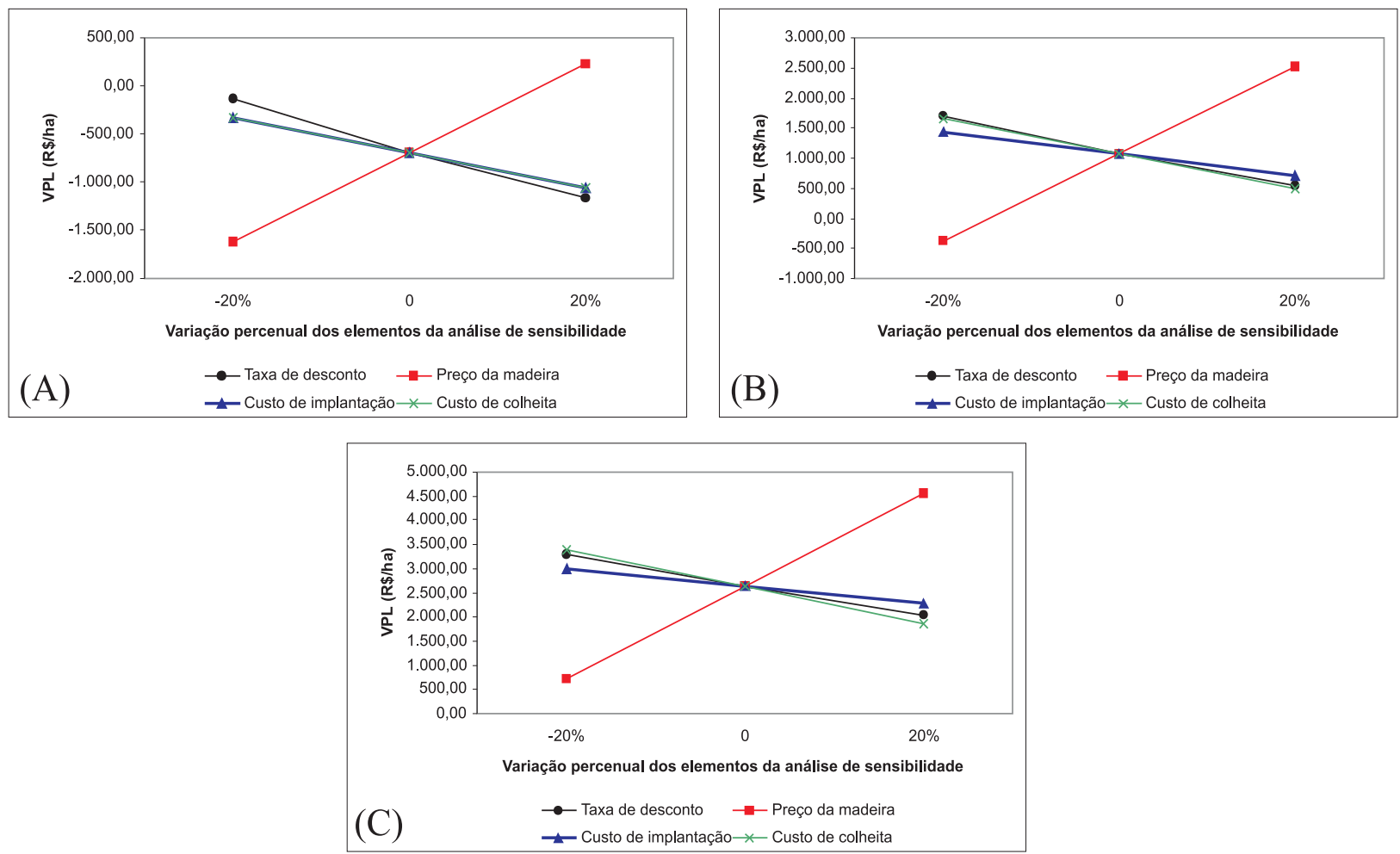

Figura 5 - Valor Presente Líquido (VPL) das três classes de produtividade: $S=20$ (A), S = 26 (B) e S = 32 (C), sem considerar os Certificados de Emissões Reduzidas (CERs).

Figure 5 - Net Current Value (NCV), for the three productivity classes: $S=20(A), S=26(B)$ and $S=32(C)$, without considering the Reduced Emission Certificates (RECs).

No local de média produtividade $(\mathrm{S}=26)$, observouse que somente um decréscimo de $20 \%$ no preço da madeira tornaria o projeto inviável financeiramente (Quadro 8 e Figura 5B). No entanto, o preço da madeira acrescido em $20 \%$ elevou o valor do VPL de R \$1.076,06/ ha para $\mathrm{R} \$ 2.516,35 / \mathrm{ha}$. Mantendo-se constantes a taxa de desconto e os demais custos, o preço da madeira poderia chegar a $\mathrm{R} \$ 42,53 / \mathrm{m}^{3}$, para que o projeto fosse considerado viável economicamente, isto é, redução de $14,94 \%$ em relação ao preço inicial de $\mathrm{R} \$ 50,00 / \mathrm{m}^{3}$.

No local de alta produtividade $(\mathrm{S}=32)$, o projeto permaneceu viável economicamente, considerando-se as variações nas variáveis analisadas (Quadro 8 e Figura 5C). O aumento de $20 \%$ no preço da madeira fez com que o VPL crescesse $72 \%$, passando de $\mathrm{R} \$ 2.628,65 /$ ha para $\mathrm{R} \$ 4.544,14 /$ ha. Mantendo-se as outras variáveis constantes, nesse local o preço da madeira poderia chegar até $\mathrm{R} \$ 36,28 / \mathrm{m}^{3}$ para que o projeto continuasse sendo viável, ou seja, poderia haver redução de $27,44 \%$ em relação ao preço adotado de $\mathrm{R} \$ 50,00 / \mathrm{m}^{3}$.
No cenário no qual se considera apenas a produção de madeira, sem os créditos de carbono, mantendose constantes a taxa de desconto, os custos e o preço da madeira e o horizonte de planejamento, o projeto instalado em local de baixa produtividade $(S=20)$ se tornaria viável economicamente, pelo critério VPL, se a produtividade aumentasse em $25,15 \%$, passando de $197,84 \mathrm{~m}^{3} /$ ha para $247,60 \mathrm{~m}^{3} / \mathrm{ha}$.

De acordo com o Quadro 9 e a Figura 6, o acréscimo de $20 \%$ no preço dos créditos de carbono influenciou muito pouco o VPL nas três classes de produtividade. Isso se deve ao fato de a receita proveniente dos CERs representar valor muito menor, em comparação com a receita obtida pela venda da madeira e com os custos.

Projetos em locais de baixa produtividade $(S=20)$ tornam-se inviáveis com o aumento de $20 \%$ na taxa de desconto e nos custos de implantação e de colheita e com a redução de $20 \%$ no preço da madeira (Quadro 9 e Figura 6A). Nesse caso, mantendo constantes a 
taxa de desconto, os custos e o preço dos CERs, o preço da madeira poderia ser de $\mathrm{R} \$ 46,23 / \mathrm{m}^{3}$, para que os projetos continuassem sendo economicamente viáveis (redução de $8,15 \%$ em relação ao preço inicial de $\left.\mathrm{R} \$ 50,00 / \mathrm{m}^{3}\right)$. Já o preço dos CERs poderia sofrer decréscimo de até 31,16\%, passando de $\mathrm{R} \$ 6,00 /$ tonelada para $\mathrm{R} \$ 4,13 /$ tonelada, se os custos e o preço da madeira permanecerem os mesmos, para que os projetos continuassem economicamente viáveis.

Quadro 9 - Análise de sensibilidade considerando os Certificados de Emissões Reduzidas (CERs)

Table 9 - Sensitivity analysis considering the Reduced Emission Certificates (RECs)

\begin{tabular}{|c|c|c|c|c|}
\hline \multirow[t]{2}{*}{ Classe de produtividade } & \multirow[t]{2}{*}{ Variável } & \multicolumn{3}{|c|}{ VPL } \\
\hline & & $-20 \%$ & 0 & $20 \%$ \\
\hline \multirow[t]{5}{*}{$S=20$} & Taxa de desconto & 978,08 & 350,12 & $-171,30$ \\
\hline & Preço da madeira & $-579,03$ & 350,12 & $1.279,26$ \\
\hline & Preço dos CERs & 125,45 & 350,12 & 574,78 \\
\hline & Custo de implantação & 710,12 & 350,12 & $-9,88$ \\
\hline & Custo de colheita & 721,78 & 350,12 & $-21,54$ \\
\hline \multirow[t]{5}{*}{$S=26$} & Taxa de desconto & $3.007,63$ & $2.392,71$ & $1.852,43$ \\
\hline & Preço da madeira & 952,42 & $2.392,71$ & $3.833,00$ \\
\hline & Preço dos CERs & $2.129,38$ & $2.392,71$ & $2.656,04$ \\
\hline & Custo de implantação & $2.752,71$ & $2.392,71$ & $2.032,71$ \\
\hline & Custo de colheita & $2.968,83$ & $2.392,71$ & $1.816,60$ \\
\hline \multirow[t]{5}{*}{$S=32$} & Taxa de desconto & $4.888,50$ & $4.234,74$ & $3.649,39$ \\
\hline & Preço da madeira & $2.319,25$ & $4.234,74$ & $6.150,22$ \\
\hline & Preço dos CERs & $3.913,25$ & $4.234,74$ & $4.555,95$ \\
\hline & Custo de implantação & $4.594,74$ & $4.234,74$ & $3.874,74$ \\
\hline & Custo de colheita & $5.000,93$ & $4.234,74$ & $3.468,54$ \\
\hline
\end{tabular}
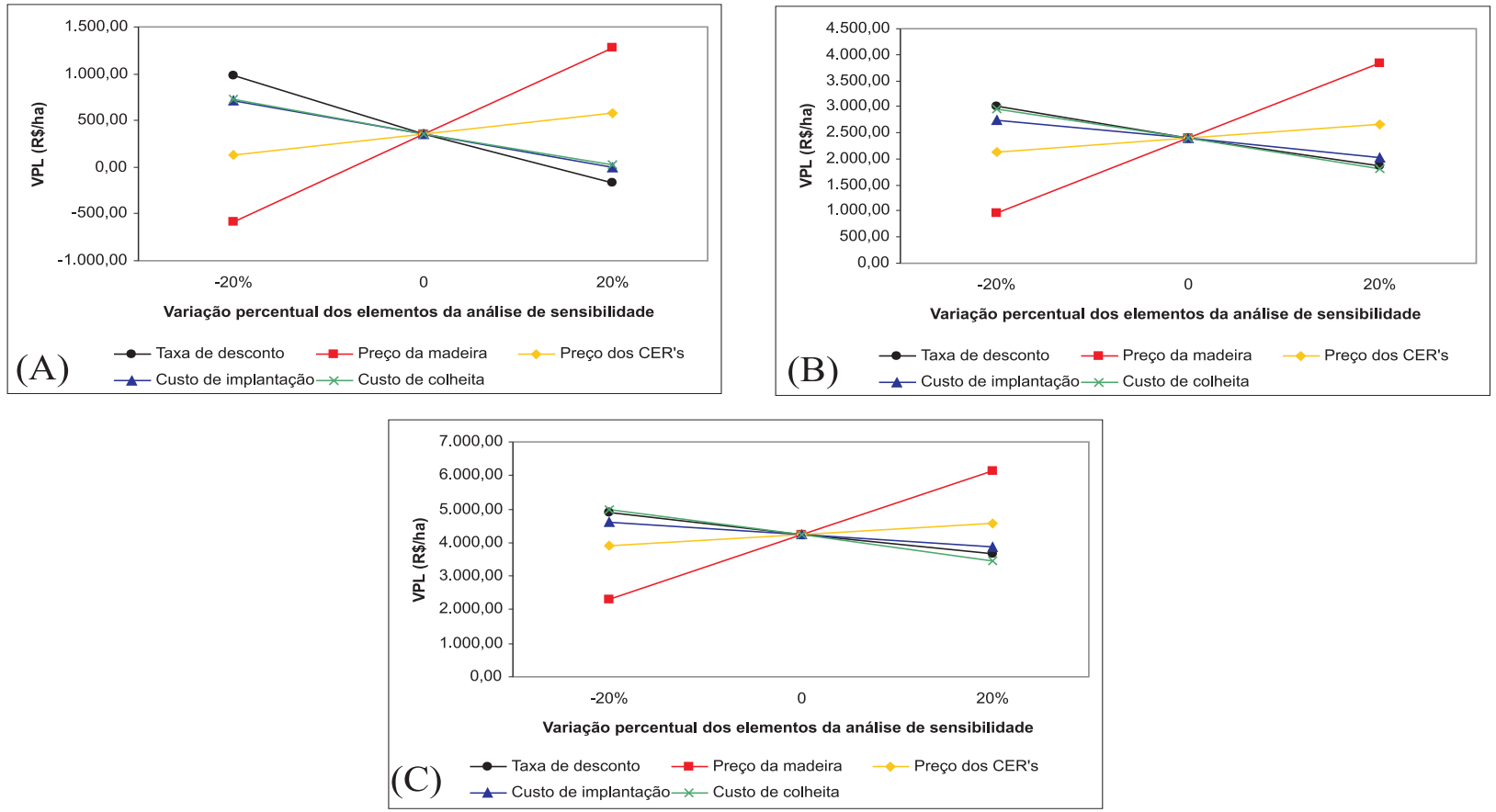

Figura 6 - Valor Presente Líquido (VPL) das três classes de produtividade: $\mathrm{S}=20$ (A), S = 26 (B) e S = 32 (C), considerandose os Certificados de Emissões reduzidas (CERs).

Figure 6 - Net Current Value (VPL), for the three productivity classes: $S=20(A), S=26(B)$ and $S=32(C)$, considering the Reduced Emission Certificates (RECs).

R. Árvore, Viçosa-MG, v.32, n.6, p.979-992, 2008 
No local de média produtividade ( $\mathrm{S}=26$ ), os projetos mantiveram-se economicamente viáveis em todas as situações analisadas (Quadro 9 e Figura 6B). O preço da madeira também foi o que mais influenciou o valor do VPL. O aumento de $20 \%$ no preço da madeira fez com que o VPL crescesse em 60,19\%, passando de $\mathrm{R} \$ 2.392,71 /$ ha para R $\$ 3.833,00 /$ ha. Mantendo-se constante a taxa de desconto em $10 \%$ a. a., os custos de implantação e colheita e o preço dos CERs, o preço inicial da madeira de $\mathrm{R} \$ 50,00 / \mathrm{m}^{3}$ poderia ser reduzido em $33,22 \%$, passando para $\mathrm{R} \$ 33,39 / \mathrm{m}^{3}$, para que os projetos continuassem sendo viáveis economicamente.

Para o local de alta produtividade $(\mathrm{S}=32)$ (Quadro 9 e Figura 6C), os resultados indicaram viabilidade econômica em todas as alternativas analisadas. Mais uma vez, o preço da madeira foi o item que mais influenciou a análise, e o aumento de $20 \%$ fez com que o VPL crescesse $45,23 \%$, passando de $\mathrm{R} \$ 4.234,74 /$ ha para R\$6.150,22/ha. Nesse caso, mantendo-se as outras variáveis constantes, o preço da madeira poderia chegar até $\mathrm{R} \$ 27,89 / \mathrm{m}^{3}$ para que os projetos continuassem viáveis economicamente, ou seja, uma redução de 44,22\% em relação ao preço inicial.

Para identificar qual a produtividade mínima que torna os projetos que consideram a produção de madeira e os créditos de carbono (cenário 2) economicamente viáveis, foi necessário estabelecer relação entre a produção de madeira e o estoque de carbono $\left(\mathrm{CO}_{2 \mathrm{eq}}\right)$, levando-se relação entre eles (Figura 7).

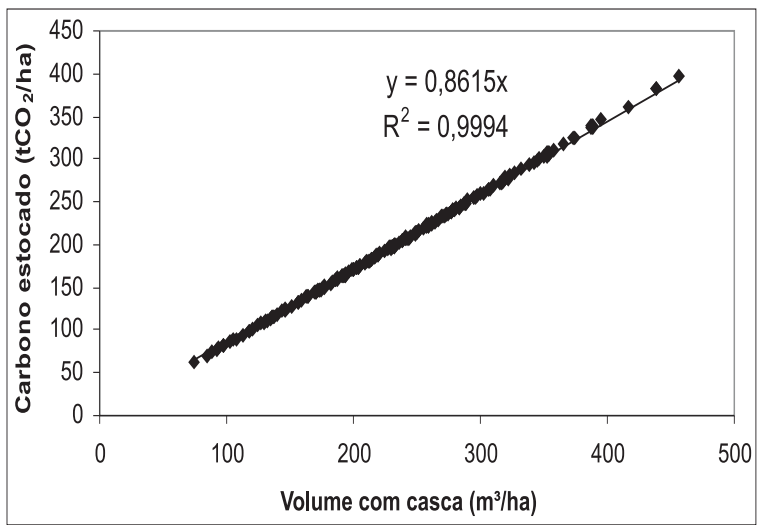

Figura 7 - Relação entre o estoque em volume e o estoque em carbono $\left(\mathrm{CO}_{2}\right.$ equivalente $)$.

Figure 7 - Relation between volume and carbon stocks $\left(\mathrm{CO}_{2}\right.$ equivalent).
Dessa forma, mantendo-se constantes os custos, os preços, a taxa de desconto e o horizonte de planejamento, na classe de menor produtividade $(\mathrm{S}=20)$ a produtividade mínima para que um projeto desta natureza fosse economicamente viável seria de $199,01 \mathrm{~m}^{3} / \mathrm{ha}$.

\section{CONCLUSÕES}

- O modelo de crescimento e produção proposto por Clutter (1983) propiciou idades técnicas de colheita coerentes com a capacidade produtiva dos povoamentos, tanto para a produção volumétrica quanto para o estoque de carbono.

As idades técnicas de colheita (ITCs) foram praticamente iguais, considerando-se o estoque volumétrico e o estoque de carbono.

As rotações econômicas foram maiores do que as idades técnicas de colheita (ITCs), para os projetos de baixa e média produtividades ( $S=20$ e $S=26$ ), independentemente da inclusão ou não dos CERs; e praticamente iguais para os de maior produtividade.

- Os CERs contribuem para a viabilidade financeira dos projetos florestais em locais de baixa produtividade, considerando-se as receitas auferidas no ano de implantação do projeto.

- Na análise de sensibilidade, o preço da madeira foi o item que mais influenciou a viabilidade econômica dos projetos. No entanto, os certificados de emissões reduzidas influenciaram muito pouco.

\section{REFERÊNCIAS}

CLUTTER, J. L. et al. Timber management: a quantitative approach. New York: John Wiley \& Sons, 1983. 333p.

FACE. Forest absorbing carbon dioxide emission. Annual Report. 1993. Arnheim: 1994.

PAIXÃO, F. A. et al. Quantificação do estoque de carbono e análise econômica de diferentes alternativas de manejo em um plantio de eucalipto. Revista Árvore, v.30, n.3, p.411-420, 2006.

R. Árvore, Viçosa-MG, v.32, n.6, p.979-992, 2008 
ROCHA, M. T. O aquecimento global e os instrumentos de mercado para a solução do problema. In: SANQUETTA, C. R. (Ed). As florestas e o carbono. Curitiba: 2002. p.1-34.

SCHUMACHER, F. X.; HALL, F. S. Logarithmic expression of timber volume. Journal of Agricultural Research, v.47, n.9, p.719-734, 1933.

SILVA, M. L.; JACOVINE, L. A. G.; VALVERDE, S. R. Economia florestal. Viçosa, MG:

Universidade Federal de Viçosa, 2002. 178p.
SOARES, C. P. B.; OLIVEIRA, M. L. R. Equações para estimar a quantidade de carbono na parte aérea de árvores de eucalipto em Viçosa, Minas Gerais. Revista Árvore, v.26, n.5, p.533-539, 2002.

VITAL, B. R. et al. Tabelas de peso seco para algumas espécies de eucalipto. Viçosa, MG: SIF, 1985. 29p. (Boletim Técnico SIF, 1).

YU. C. M. Caracterização e tipologia dos projetos de seqüestro de carbono no Brasil. In:

SANQUETTA, C. R. (Ed). As florestas e o carbono. Curitiba: 2002. p.59-87. 